\title{
ОЦЕНКА ЭФФЕКТИВНОСТИ ВСПОМОГАТЕЛЬНЫХ РЕПРОДУКТИВНЫХ ТЕХНОЛОГИЙ В РАННИЕ СРОКОВ БЕРЕМЕННОСТИ
}

\section{EVALUATION OF THE EFFECTIVENESS OF ASSISTED REPRODUCTIVE TECHNOLOGIES IN EARLY PREGNANCY}

\section{T. Kamaeva}

Summary. Infertility is one of the most actual problems of modern medicine. Currently, assisted reproductive technologies are one of the most effective treatments for many factors reproductive function. Unfortunately, the IVF procedure does not exclude such adverse pregnancy outcomes as spontaneous miscarriage or early pregnancy. This article describes methods of predictive significance of ultrasonic method for complicated pregnancy.

Keywords: infertility, ultrasound diagnostics, in vitro fertilization.

\author{
Камаева Татьяна Александровна \\ К.м.н., ФГБОУ ВО Хакасский государственный \\ университет им. Н. Ф. Катанова, г. Абакан \\ tatyankamaev@yandex.ru
}

Аннотация Бесплодие - одна из актуальных проблем современной медицины. В настоящее время экстракорпоральное оплодотворение является одними из самых результативных методов лечения нарушений репродуктивной функции. Процедура экстракорпорального оплодотворения (далее - ЭКО) не исключает и неблагоприятные исходы беременности как самопроизвольный выкидыш или замершая беременность. В настоящей статье приведены методы прогностической значимости ультразвукового метода исследования для осложненного течения беременности.

Ключевые слова: бесплодие, ультразвуковая диагностика, экстракорпоральное оплодотворение.

на перенос эмбриона (далее ПЭ) и 56-78\% - на число клинически наступивших беременностей [7]. Согласно данным литературы у женщин после ЭКО и ПЭ отмечается высокий процент перинатальных потерь и заболеваемости новорожденных. Ультразвуковой метод диагностики беременности после ЭКО считается общепризнанным и проводится всем женщинам на 21-28 день после переноса эмбриона, что соответствует гестационному сроку 5-6 недель [4]. Учитывая особую ценность здоровья детей, родившихся после столь непросто наступившей беременности, целью данного исследование является прогностическая значимость УЗИ при детальном исследовании хориона и кровотока в нем. При выявлении неблагоприятных данных по прогнозу беременности после ЭКО возможно коррекция терапии для поддержки данной беременности, что возможно предотвратит неблагоприятный ее исход.

\section{Материалы и методы исслеАования}

В качестве основной группы представлено 240 пациенток с бесплодием, прошедших программу экстракорпорального оплодотворения. Возраст обследуемых женщин в основной группе варьировал от 26 до 42 лет (35 \pm 4$)$, в анамнезе всех женщин (100\%) имелись отягощающий факторы. Основными показаниями к проведению ЭКО было трубно-перитонеальное бесплодие - в 150 $(62,4 \%)$ случаях, мужской фактор бесплодия отмечен 
у 48 семейных пар (20\%), эндокринное бесплодие - 24 (10\%), смешанного генеза - 18 (7,5\%).

Всем женщинам основной группы проведена стимуляция овуляции по короткому протоколу, в целях исключения многоплодной беременности перенос в полость матки 1 эмбриона.

В качестве контрольной группы обследованы 240 пациенток после естественного зачатия, не имеющие экстрагенитальной патологии и гинекологических заболеваний. Возраст беременных в группе сравнения соста-

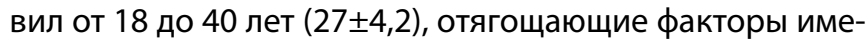
лись лишь у 140 (60\%) пациенток.

Ультразвуковое исследование органов малого таза проводилось на стационарном ультразвуковом аппарате экспертного класса Samsung Medison Accuvix A30 конвексным и трехмерным ретовагинальным датчиком 5-9 МГц.

Применялся 2Д режим, цветное допплерометрическое картирование, импульсный допплер и ЗД реконструкция проводилось 240 беременным после ЭКО с положительным результатом ХГЧ на 21-28 день после переноса эмбриона, что соответствует 5-6 неделе гестационного срока. В контрольной группе обследование проведено на 5-6 неделе.

С 5 недели гестации формируется нервная трубка эмбриона. К этому сроку копчико-теменной размер достигает 3 мм, образуются сомиты, начинают развиваться зачатки сердца, легких, щитовидной железы, пупочных сосудов. В нервной трубке дифференцируются передний, средний и задний мозговые пузыри. С помощью ультразвука возможно определить формирующееся сердце, на этом сроке устанавливается замкнутое кровообращение через желточный мешок и ножку зародыша $[1,7,12,15,17]$. В этот период мы визуализировали амниотическую полость, желточный мешок, дифференцировали вентральная и дорсальная поверхности эмбриона, головной и тазовый конец, при исследовании на данном сроке дифференциация внутренних органов невозможна. Трансвагинальная эхография с использованием цветного допплеровского картирования позволила определить пульсацию сердечной трубки. В месте имплантационной площадки формируются типичные мезенхимальные ворсины, с противоположной стороны от зоны имплантации ворсины останавливаются в своем развитии. В эти же сроки проходит первая волна инвазии трофобласта и формируется межворсинчатое пространство, которое также возможно для визуализации.

На 6-й неделе гестации мы определяли зачатки рук и ног, удлиненная почка передней конечности, появ- ляется зачаток кистевой пластины, нижняя конечность остается в виде почки. В этот период возникают зачатки парных полушарий головного мозга, продолжается формирования органов чувств (глаз и уха). В замкнутой нервной трубке определялись по УЗИ отделы мозга и обозначены полушария головного мозга и мозжечка. На этом сроке формируется односторонний ток крови через сердце, практически завершается подразделение сердца на камеры, сердце к этому сроку функционирует. В 6 недель начинает определятся первичная почка, зачатки мочеточника, зачатки половых желез, а также печень, желчный пузырь, поджелудочная железа, различные отделы кишечного тракта [7, 14, 16]. Продолжается первая волна инвазии цитотрофобласта в сторону спиральных артерий с формированием венозных коллекторов. К концу 6-й недели гестации копчико-теменной размер эмбриона достигает 6 мм. В этот период появляются жаберные дуги, формируется зрительный пузырь, начинается дифференцировка гипофиза. При ультразвуковой визуализации в данном сроке начинает определяться промежуточный и средний мозг, полость четвертого желудочка и заднего мозга. Формируется кишечник и передняя брюшная стенка. При проведении ультразвукового сканирования мы определяли амниотическую полость, желточный мешок, эмбрион длиной 4-5 мм. Четко дифференцируются вентральная и дорсальная поверхности эмбриона, головной и тазовый конец, видны почки передних и задних конечностей. Нами проводилось прицельная визуализация заднего мозга, зачатков парных полушарий головного мозга, полости четвертого желудочка.

Ультразвуковое исследование проводилось в соответствии с Клиническим протоколом через 21 день после подсадки эмбриона, что соответствует сроку 5-6 недель и заключалась в:

1. Определение среднего диаметра плодного яйца, КТР, диаметра желточного мешочка, локализации хориона в режиме серой шкалы.

2. При цветном допплерометрическом картировании определялось показатели кровотока в маточных артериях, васкуляризация хориона.

3. При проведении ЗД реконструкции хориона рассчитывали VI - индекс васкуляризации, который отражает процентное содержание сосудистых элементов в интересующем объеме плацентарной ткани и $\mathrm{FI}$ - индекс кровотока, который отражает количество клеток крови, транспортируемых в момент исследования, т.е. интенсивность кровотока.

\section{Результаты и обсужления}

Проведение ультразвуковых исследований в серой шкале после ЭКО и после естественного зачатия в 5-6 
Таблица 1. Характеристики кровотока при ультразвуковом исследовании хориона в 5-6 недель гестации в контрольной группе

\begin{tabular}{|l|l|l|l|l|l|}
\hline $\begin{array}{l}\text { Срок гестации } \\
\text { при проведе- } \\
\text { нии Узи }\end{array}$ & $\begin{array}{l}\text { Количество наблюде- } \\
\text { ний }\end{array}$ & $\begin{array}{l}\text { IR маточных арте- } \\
\text { рий }\end{array}$ & $\begin{array}{l}\text { Средний объем } \\
\text { хориона, см }\end{array}$ & $\begin{array}{l}\text { Индекс } \\
\text { васкуляризации }\end{array}$ & $\begin{array}{l}\text { Индекс крово- } \\
\text { тока }\end{array}$ \\
\hline 5 недель & 135 & $0,61 \pm 0,07$ & $5,3 \pm 0,7$ & $13,8 \pm 1,0$ & $32,4 \pm 1,1$ \\
\hline 6 недель & 105 & $0,48 \pm 0,1$ & $8,7 \pm 0,67$ & $18,1 \pm 0,9$ & $33 \pm 1,3$ \\
\hline
\end{tabular}

Таблица 2. Количество обследованных женщин основной группы, имеющих отклонения в показателях при ультразвуковом исследовании хориона в 5-6 недель гестации

\begin{tabular}{|c|c|c|c|c|c|c|c|c|c|}
\hline \multirow[b]{2}{*}{$\begin{array}{l}\text { Срок гестации } \\
\text { при проведе- } \\
\text { нии УзИ }\end{array}$} & \multirow[b]{2}{*}{$\begin{array}{l}\text { Количе- } \\
\text { ство на- } \\
\text { блюдений }\end{array}$} & \multicolumn{2}{|c|}{ IR маточных артерий } & \multicolumn{2}{|c|}{$\begin{array}{l}\text { Средний объем хори- } \\
\text { она, см }{ }^{3}\end{array}$} & \multicolumn{2}{|c|}{$\begin{array}{l}\text { Индекс } \\
\text { васкуляризации }\end{array}$} & \multicolumn{2}{|c|}{ Индекс кровотока } \\
\hline & & $\begin{array}{l}\text { Кол-во } \\
\text { женщин } \\
\text { име- } \\
\text { ющие } \\
\text { отклоне- } \\
\text { ния }\end{array}$ & $\begin{array}{l}\text { Кол-во } \\
\text { женщин } \\
\text { с норма- } \\
\text { тивным } \\
\text { значением }\end{array}$ & $\begin{array}{l}\text { Кол-во } \\
\text { женщин } \\
\text { име- } \\
\text { ющие } \\
\text { отклоне- } \\
\text { ния }\end{array}$ & $\begin{array}{l}\text { Кол-во } \\
\text { женщин } \\
\text { с норма- } \\
\text { тивным } \\
\text { значением }\end{array}$ & $\begin{array}{l}\text { Кол-во } \\
\text { женщин } \\
\text { имеющие } \\
\text { отклоне- } \\
\text { ния }\end{array}$ & $\begin{array}{l}\text { Кол-во } \\
\text { женщин } \\
\text { с норма- } \\
\text { тивным } \\
\text { значением }\end{array}$ & $\begin{array}{l}\text { Кол-во } \\
\text { женщин } \\
\text { имеющие } \\
\text { отклоне- } \\
\text { ния }\end{array}$ & $\begin{array}{l}\text { Кол-во } \\
\text { женщин } \\
\text { с норма- } \\
\text { тивным } \\
\text { значением }\end{array}$ \\
\hline 5 недель & 204 & 75 & 129 & 123 & 81 & 120 & 84 & 111 & 93 \\
\hline 6 недель & 36 & 9 & 27 & 18 & 18 & 24 & 12 & 9 & 27 \\
\hline
\end{tabular}

недель не отличалась от рутинного обследования беременных. Данное исследование значимо для диагностики срока и локализации беременности, исключения замершей беременности и анэмбрионии.

При проведении цветного допплерометрического картирования в маточных артериях выявлено достоверное увеличение показателей IR у беременных в основной группе в 55\% случаях -132 пациентки. При дальнейшем наблюдении у всех женщин реализовалась угроза самопроизвольного выкидыша. В контрольной группе увеличение IR в маточных артериях выявлено всего лишь в 18,7\% -45 женщин. Показатель резистентности кровотока в маточных артериях является прогностически значимым для ведения беременных в группе риска по невынашиванию, преэклампсии и плацентарной недостаточности.

Кроме того, при проведении цветного допплерометрическом картировании визуализировался хорион, определялась его локализация и степень его васкуляризации.

В результате проведенного исследования в контрольной группе уточнены ультразвуковые характеристики физиологического течения беременности на раннем сроке (таблица 1).

При исследовании хориона в режиме ЗД в контрольной группе были определены параметры средне- го объема хориона - 5,3-8,7см³, индекс васкуляризации - 13,8-18,1 и индекс кровотока - 32,4-33. Данные значения были приняты за нормативные для данных сроков беременности.

При проведении ультразвукового исследование в основной группе регистрировались изменения в кровоснабжении хориона на ранних сроках в 5-6 недель у 183 женщины - 76,2\% (таблица 2).

Из таблицы видно, что наиболее диагностически значимыми являются показатели среднего объема хориона и индекс васкуляризации.

В основной группе беременность осложнились угрозой прерывания беременности в 76,2\% случаев, преждевременными родами в 45,6\%, преэклампсией в 24,1\%, синдромом задержки развития плода в 45,9\%. Все данные исходы зарегистрированы у женщин, имеющие отклонения в показателях при ультразвуковом исследовании на ранних сроках беременности.

В контрольной группе отклонение в показателях кровоснабжения хориона диагностировано в 18,9\% случаев. Осложнения беременности возникли в 25,4\%.

При проведении анализа историй новорожденных выявлено, что после ЭКО родились дети с массой тела

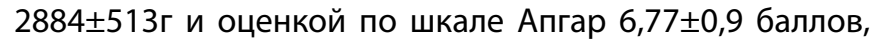
тогда как у женщин с естественным оплодотворением 
масса детей составила $3193 \pm 425$ г и оценкой по шкале Апгар 7,86 $\pm 0,7$ баллов.

\section{Зак^ючение}

1. В результате проведенного исследования нами подтверждено, что беременность после экстракорпорального оплодотворения относится к беременности высокой группы риска акушерских осложнений.

2. Течение беременности, наступившей с использованием ЭКО сопровождаются угрозой прерывания беременности в 76,2\% случаев Группа высокого риска по невынашиванию у беременных после ЭКО диктует необходимость более детального подхода к проведению вспомогательных репродуктивных технологий и качественной прегравидарной подготовки
3. Трехмерное сканирование в сочетании с допплерометрией, расширяют возможности ультразвуковой диагностики, и способствуют раннему выявлению нарушений в плодном яйце, что является ключевым в разработке мероприятий, необходимых для обеспечения эффективной перинатальной охраны плода и новорожденного. Наиболее клинически значимыми при ультразвуковой исследовании беременности раннего срока являются средний объем хориона и индекс васкуляризации хориона.

4. Более углубленное ультразвуковое исследование с применением допплерометрии и 3х мерной реконструкции хориона в ранние сроки беременности после ЭКО позволит выявить возможные осложнения, отнести беременную в соответствующую группу риска в целях своевременной коррекции медикаментозной поддержи беременности и улучшения перинатальных исходов.

\section{ЛИТЕРАТУРА}

1. Аншина, М.Б. ЭКО в естественных циклах (клиническая лекция) / Проблемы репродукции [Электронный ресурс].— 2008. — № 4.

2. Доброхотова Ю. Э., Зубарев А. Р., Залесская С. А., Зубарева Е. А., Сапрыкина Л. В., Демидова А. К. Оценка формирующегося маточно-плацентарного кровотока у пациенток с угрозой прерывания на фоне дефицита прогестерона в 1 триместре беременности. / Акушерство и гинекология.— 2016 г.—№ 6.

3. Назаренко Т. А. Значение оценки овариального резерва в лечении бесплодия у женщин старшего репродуктивного возраста / Проблемы репродукции [Электронный ресурс]. - 2005.- № 2 .

4. Колпинский Г. И., Камаева Т. А., Прогностическая ценность ультразвукового метода исследования при диагностике беременности ранних сроков после ЭКО. / Современная наука: актуальные проблемы теории и практики. Серия «Естественные и технические науки»,_2017, -№ 3-4, -С94-97.

5. Корсак В.С. Исследование эндометрия у пациенток с трубно-перитонеальным бесплодием на этапе подготовки к ЭКо / Проблемы репродукции [Электронный ресурс].—2005.— № 2 .

6. Подзолкова, Н. М. Особенности ВРТ у пациенток с ожирением (обзор литературы) / Проблемы репродукции [Электронный ресурс]. — 2008 . — № 4.

7. Ускова М. А. Рациональные подходы к лечению трубно- перитонеального бесплодия (обзор литературы) / Проблемы репродукции [Электронный ресурс].—2009.— № 4 .

8. Тишкевич 0. Л. Эффективность ЭКО и частота многоплодной беременности в зависимости от числа и качества переносимых эмбрионов у женщин разного возраста / Проблемы репродукции [Электронный ресурс]. - 2008. — № 2.

9. Фалин Л. И. Эмбриология человека. Атлас. - М.: Медицина, 1976. - 544 с.

10. Федорова М. В. Калашникова Е. П. Плацента и ее роль при беременности.—М.: Медицина, 1986. — 265 c.

11. Bodemer Ch. W. Modern embryology // N.Y.,1968; 475p.

12. Bentz E. K., Kenning M., Schneeberger C., Kolbus A., Haber J. C., Hefler L. A., Tempfer C. B. OCT — 4 expression in follicular and luteal phase endometrium: a pilot study. Reprod. Biol. Endocrinol. 2010; 8:38.

13. Corliss C. E. Patten`s human embryology. Elements of clinical development // McGroww.Hill Book Company, A Blackiston Publication, N.Y., a.0., 1976; 470 p.

14. Gotte M., Steabler A., Buchweitz 0., Kelsch R., Schuring A. N., Kiesel L. Increased expression of the adult stem cell marker Musashi -1 in endometriosis. J. Pathol.2008; 215(3): 317-29.

15. Edwards R. G. Sciense et ethique de la segmentation des embrions humains in vitro // Contracpt. Fertil Sex 1986;14:4:313.318.

16. England M. A. Farbatlas der Embriologie // F. K. Shattaner Verlag. — Stuttgart.N.Y.1985;25.

17. Pretorius D. H., Nelson T. R., Baergen R. N., Pai E., Cantrell C. Imaging of placental vasculature using three.dimensional ultrasound and color power Doppler: a preliminary study // Ultrasound Obstet Gynecol, 1998 Jul; 12 (1): 45.9.

18. Welsh A.W., Humphries K., Congrove D. O., Taylor M.J., Fisk N.M. Developments of three-dimensional power Doppler ultrasound imaging of fetoplacental vasculature // Ultrasound Med Biol, 2001 Sep; 27 (9): 1161.70. 